\title{
THE
}

\section{Nutrition Knowledge, Attitudes, and Fruit and Vegetable Intake as Predictors of Head Start Teachers' Classroom Mealtime Behaviors}

\author{
Katherine Halloran \\ University of Rhode Island \\ Kathleen S. Gorman \\ University of Rhode Island, kgorman@uri.edu \\ Megan Fallon \\ University of Rhode Island \\ Alison Tovar \\ Flilow this and additignal works at: https://digitalcommons.uri.edu/nfs_facpubs
}

The University of Rhode Island Faculty have made this article openly available.

Please let us know how Open Access to this research benefits you.

This is a pre-publication author manuscript of the final, published article.

Terms of Use

This article is made available under the terms and conditions applicable towards Open Access Policy Articles, as set forth in our Terms of Use.

\section{Citation/Publisher Attribution}

Halloran, K., M, Gorman, K., Fallon, M., \& Tovar, A. (2018). Nutrition Knowledge, Attitudes, and Fruit and Vegetable Intake as Predictors of Head Start Teachers' Classroom Mealtime Behaviors. Journal of Nutrition Education and Behavior, 50(4), 340-348. doi: 10.1016/j.jneb.2017.10.015

Available at: http://dx.doi.org/10.1016/j.jneb.2017.10.015

This Article is brought to you for free and open access by the Nutrition and Food Sciences at DigitalCommons@URI. It has been accepted for inclusion in Nutrition and Food Sciences Faculty Publications by an authorized administrator of DigitalCommons@URI. For more information, please contact digitalcommonsgroup@uri.edu. 


\section{INTRODUCTION}

Childhood obesity is a serious public health problem with approximately $14 \%$ of

4 preschool aged children in the U.S. considered to be obese. ${ }^{1}$ Given that children are spending an

5 increasing amount of time in child care, with $61 \%$ of preschoolers in center-based care, child

6 care teachers play an important role in influencing the diets of children, primarily through their

7 mealtime interactions. ${ }^{2-6}$ Although teacher nutrition knowledge and attitudes are thought to

8 influence their mealtime behaviors with children, ${ }^{7,8}$ evidence is still lacking. Similarly, it is

9 unclear if child care teachers' own dietary behaviors influence their mealtime behaviors with

10 children. ${ }^{9,10}$ Given that children who are in center-based care consume up to $75 \%$ of their daily

11 meals in the child care setting, there is a need to further understand teacher nutrition knowledge,

12 attitudes, dietary behaviors and their classroom mealtime behaviors in order to inform future

13 interventions.

14 A number of mealtime behaviors, including feeding practices, have been associated with

15 better health outcomes in children. ${ }^{11-15}$ Controlling feeding practices, for example, exerting

16 pressure to eat, restricting foods and using food as a reward have been associated with less

17 optimal outcomes, such as lower intake of vegetables and increased intake of unhealthy "off-

18 limits" foods, even when not hungry. ${ }^{16-22}$ In contrast, optimal behaviors are those considered

19 more responsive and positive ${ }^{23}$ (e.g., responding to children's signals of hunger and satiety,

20 responding positively to children's attempts to self-feed), where caregivers allow children to

21 control the amount of food they eat. These aforementioned practices have been associated with

22 improved ability to self-regulate energy intake. ${ }^{24}$ Although there are a growing number of studies

23 exploring the mealtime behaviors and feeding practices of child care teachers, ${ }^{10,25}$ most of the 
24 literature has focused primarily on parents. While parents and teachers vary when it comes to the

25 role they play in influencing children's eating, ${ }^{26,27}$ the parent feeding literature provides an

26 important foundation for examining the feeding practices of child care teachers.

27 Some studies that have included child care teacher feeding practices have explored how

28 practices vary among teachers. For example, teachers with more education and experience

29 engaged in more optimal mealtime behaviors ${ }^{7}$ (e.g., sitting with children during the meal,

30 consuming the same foods as children). The association between teachers' own nutritional

31 knowledge and attitudes in relation to their mealtime behavior with children, above and beyond

32 teachers' general education and experience, is less well understood, and findings are mixed. One

33 study reported a positive association between mealtime behavior of teachers and nutrition

34 knowledge and attitudes, ${ }^{7}$ while others reported no demonstrable effect of improved nutrition

35 knowledge on teacher behavior. ${ }^{28}$ A better understanding of how nutrition knowledge and

36 attitudes influence teacher behavior, however, has important implications for teaching education.

37 Research examining nutrition attitudes and perceptions among Head Start teachers revealed

38 common beliefs that children's eating behaviors and weight status were not connected and

39 skepticism regarding the definition of overweight. ${ }^{29}$ Additional research has also revealed

40 nutrition knowledge to be low among child care providers. ${ }^{9}$ A recent study examining Head Start

41 teachers found that $97 \%$ of teachers could only answer 3 or fewer of 5 nutrition questions

42 correctly. Furthermore, $24 \%$ of Head Start directors felt that lack of knowledge among teachers

43 about how to encourage healthy eating was an important impediment to obesity prevention. ${ }^{30}$

44 Learning more about teacher nutrition knowledge and attitudes may help improve teacher

45 classroom mealtime interactions with children. 
The study of teacher knowledge and attitudes as an influence on their own health

47 promoting behaviors, and ultimately on children's behaviors, is supported by a number of

48 theories including Bronfenbrenner's ecological model, ${ }^{31}$ Bandura's Social Cognitive Theory, ${ }^{32}$

49 and the Health Belief Model. ${ }^{33}$ Both Bronfenbrenners' and Banduras' theories emphasize that

50 important adults in a child's life, including teachers, influence behavior through several

51 mechanisms including education, normative practices, and social support. Role-modeling may

52 also be a factor in health promoting behavior. There is some limited research to show that more

53 positive health characteristics and behaviors in one's own life may translate to efforts to improve

54 other's health habits. For example, lower body mass index (BMI) among doctors is associated

55 with more frequent discussions about weight loss with patients, compared to those with higher

56 BMI's. ${ }^{34}$ The behaviors of Women, Infants and Children (WIC) staff were also examined in the

57 context of obesity prevention. Compared to a control group, staff members who received an

58 intervention to make healthier food choices and be more physically active were more likely to

59 report making positive changes in counseling WIC parents about their children's weight. ${ }^{35}$

60 Head Start has been a pioneer in setting policies related to food and nutrition for their

61 students. For example, Head Start programs are required by Federal Program Performance

62 Standards to provide nutrition training to staff as well as families. ${ }^{36}$ Research indicates high

63 levels of adherence when it comes to centers carrying out these trainings, with $92 \%$ of programs

64 teaching staff routines pertinent to feeding children and $84 \%$ offering workshops for parents for

65 preparing and buying healthy foods. ${ }^{37}$ Some research suggests, however, that Head Start teachers

66 have poor overall health and diets. For example, a study looking at 173 Head Start teachers in

67 Texas found low fruit and vegetable consumption, high consumption of fast foods and sugar

68 sweetened beverages, and self-reported poor nutritional health for teachers as a whole. ${ }^{9}$ 
69 Additionally, high rates of overweight and obesity have been reported among Head Start teachers

70 across studies. ${ }^{9,10}$ As compared to women with similar socio-demographic backgrounds, Head

71 Start teachers were found to have poorer physical and mental health and higher rates of obesity,

72 diabetes, and high blood pressure. ${ }^{38}$ Examining teacher's diets in relation to their behaviors with

73 children is an important avenue of study. Children of low socio-economic status are particularly

74 at risk for consuming unhealthy foods and obesity, ${ }^{39}$ therefore, understanding factors within their

75 environments could have important implications for obesity preventions.

76 The purpose of this study was to examine the association between nutrition knowledge,

77 attitudes, and fruit and vegetable intake among Head Start teachers and their mealtime behaviors

78 (self-report and observed) in the classroom with children. Higher nutrition knowledge, more

79 positive nutrition attitude scores, and higher fruit and vegetable consumption were expected to be

80 associated with higher mealtime behavior scores in the classroom with children. Head Start

81 centers were selected to represent a homogenous set of child care settings, in order to minimize

82 center level differences in examining associations.

\section{METHODS}

\section{Study Design, Participants and Recruitment}

86 The study was a cross-sectional design collecting both survey and observational data

87 between September 2014 and May 2015 in 16 Head Start centers across Rhode Island. The study

88 was approved by the Institutional Review Board (IRB) at the University of Rhode Island in

89 September of 2014.

90 Participants were a convenience sample of 85 Head Start teachers (i.e., head, assistant,

91 special education and teacher's aides). Teachers were recruited with the assistance of the Rhode 
92 Island Department of Education Child and Adult Care Food Program (CACFP) director and

93 initial contact was made to the 7 Head Start Directors in the state. Six of the 7 directors

94 responsible for 22 of the 32 Head Start centers across the state agreed to participate in the study

95 and alerted teachers in their centers about the study. Teachers were instructed to contact the

96 researcher and those teachers who agreed to participate scheduled a classroom visit where

97 consent was signed prior to the meal observation. Participants were assured both anonymity and

98 confidentiality in their responses both verbally and in writing (informed consent). Researchers

99 recruited other classroom teachers during these on-site visits. A total of 86 teachers were in

100 contact with the researcher, either through phone/email (19\%) or in-person (81\%), and 85

101 teachers enrolled in the study. One person declined to participate.

\section{Procedures}

103 Classroom observations occurred during 66 lunchtime meals (78\% of meals observed)

104 and 19 breakfasts (22\% of meals observed). Consistent with Head Start meal patterns, breakfast

105 typically included 1 fruit/1 vegetable (or 2 fruit or 2 vegetable servings), 1 bread/grain and 1

106 milk serving, while lunch, included all of the above, in addition to a serving of protein. ${ }^{40}$

107 Researchers coded teachers on 42 mealtime behaviors (e.g., whether teacher ate same foods as

108 child, whether teacher talked with the children about the foods they were eating). Researchers

109 also collected data on the administration of the meal (e.g., what time meal started/ended, how

110 foods were served). Observations were performed at a removed distance from the table and

111 researchers did not interact with the children. Following the observation, teachers completed a

112 self-administered survey at their convenience and returned it to the researcher at the next visit or

113 by mail. Upon completion of the study (classroom observations and surveys), participants were 114 given a $\$ 35$ gift card. 


\section{Measures}

116 Nutrition knowledge. A 12-item multiple choice nutrition knowledge questionnaire was

117 developed for use in this study. Two faculty members, one each in Nutrition and Psychology,

118 evaluated the measure for content validity by examining whether items were in line with current

119 United States Department of Agriculture ${ }^{41}$ (USDA) recommendations. The measure was then

120 pre-tested with graduate students in Nutrition and Psychology, further modified based on this

121 pre-test, and subsequently piloted with 5 Head Start teachers. Participants were asked to select

122 the correct answer to questions about basic healthy eating and nutrition principles in line with

123 current dietary guidelines suggested by the USDA (e.g., How many cups of vegetables should a

124 moderately active adult eat per day? Which behavior specific message supports a healthy diet?).

125 Each correct answer received 1 point and scores were summed, yielding a total score ranging

126 from $0-12$ (alpha=0.62). Higher scores indicated higher levels of nutrition knowledge.

127 Nutrition attitudes. Nutrition attitudes were assessed using the Nutrition Attitudes Inventory, ${ }^{7}$ a

128 27-item self-report tool addressing attitudes about fostering healthy eating habits in early

129 childhood (e.g., mealtime should be used as an opportunity to educate children, teachers should

130 not force children to eat foods). The measure was originally pre-tested with registered dietitians

131 and faculty in child development and early childhood education in a past validation study. The

132 measure was found to have an internal consistency of 0.69 (alpha) in a previous study. ${ }^{7}$

133 Participants were asked to respond to statements on a 3-point scale (Disagree=1; No Opinion=2;

134 Agree =3). Scores were summed (range: 27-81) with higher scores indicating high agreement

135 with attitudes that have been identified as important in supporting children's healthy eating. In

136 the current study, the internal consistency of the measure was 0.62 (alpha). 
137 Fruit and vegetable intake. Fruit and vegetable intake was assessed using The National Cancer

138 Institute (NCI) Fruit and Vegetable Screener (FVS) (By-Meal). ${ }^{42}$ The FVS is a 14-item tool that

139 assesses daily consumption of fruits and vegetables in cups. The recommended minimum of cups

140 of fruits and vegetables per day for adult women is 3.5 (variation is based on age, sex and level

141 of physical activity) (USDA, 2014). ${ }^{41}$ In a past validation study, fruit and vegetable intake using

142 the FVS was found to have comparable (convergent) validity with fruit and vegetable intake on

143 both the 24-hour recall $(r=0.67)$ and the Food Frequency Questionnaire (FFQ) $(r=0.68) .{ }^{43}$ The

144 measure was also found to have adequate internal consistency in the current study (alpha=0.74).

145 Mealtime behavior observation. Mealtime behaviors were assessed using a modified version of

146 the Eating Occasions-Staff Behaviors Scale, one of 16 scales from The Environment and Policy

147 Assessment and Observation (EPAO). ${ }^{44}$ The EPAO is a 75-item scale designed to assess the

148 nutrition and physical activity environment in child care settings. The instrument was originally

149 validated in a child care environment where items were evaluated for both content and clarity,

150 then subsequently revised. Inter-observer agreement of the Eating Occasions-Staff Behaviors

151 Scale was estimated using intra-class correlation coefficient $(\mathrm{ICC}=0.78)$ in a previous study. ${ }^{44}$

152 For the purposes of the current study, 9 original items from the Eating Occasions-Staff Behaviors

153 Scale, plus an additional 38 items designed by the authors, comprised the 47-item EPAO-

154 Expanded Feeding Practices (EPAO-EFP). The EPAO-EFP assessed the occurrence of 42

155 mealtime behaviors and included 5 additional questions about the administration of the meal

156 (i.e., breakfast vs. lunch, what time meal started/ended, how long the meal lasted, what foods of

157 a behavior (e.g., whether teacher ate same foods as child, whether teacher consumed sweet or

158 salty snacks) and 27 items captured the frequency (Never=1;1-2 times=2; 3 or more times=3) of

159 behaviors (e.g., whether teacher talked with the children about the foods they were eating, 
160 whether teachers rushed children to eat). Total scores were summed with higher scores indicating

161 more optimal mealtime behaviors (e.g., enthusiastically role modeling healthy eating, responding

162 to children's signals of hunger) (range: 42-111) (alpha=.70). Interrater reliability (Kappa=.83)

163 was established between 2 observers ( $\mathrm{KH}$ and $\mathrm{MF}$ ) at the beginning of the study and confirmed

$164($ Kappa=.84) at a later point in the study. A Kappa value between 80-100\% indicates an 'almost

165 perfect' level of interrater reliability. ${ }^{45}$

166 Mealtime behavior self-report. The Teacher Reported-Feeding Practices (TR-Feeding

167 Practices), is part of 1 of 3 surveys from the Environment and Policy Assessment and

168 Observation Self-Report (EPAO-SR), an 800-item self-administered version of the EPAO (for

169 both teachers and directors) assessing classroom behaviors. ${ }^{46}$ The measure was originally

170 validated by both child care experts and parents for content validity by examining relevance,

171 format and clarity of items. ${ }^{46}$ Reliability evidence was collected on individual staff feeding

172 behavior items in a previous study. One and 4-day estimates ranged from 0.06 to 0.92 , with most

173 scores above 0.30 . The TR-Feeding Practices contains 24 items that ask teachers to rate

174 statements on a scale from 1 to 6 to the degree to which they engaged in certain behaviors (e.g.,

175 praise children when they try a new food, encourage children to eat a wide variety of foods)

176 (Never=1 to Always=6) or agreed with certain behaviors (e.g., communicate the importance of

177 healthy eating to parents, role mode healthy behaviors) (Strongly disagree=1 to Strongly

178 agree=6). Scores are summed to produce a total score with higher scores indicating more optimal

179 mealtime behavior (range: 24-144). In the current study, the internal consistency was 0.65

180 (alpha).

181 Demographics. Teachers completed a 24-item Demographics, Health and Center Practice survey

182 developed for this study. The survey was created using pre-existing items from 2 validated 
183 measures previously used with Head Start populations, the Head Start on Healthy Living Health

184 Behavior Survey and The Head Start Teacher Survey. ${ }^{9,47}$ Variables used in this study include

185 teacher age, years as a child care teacher, years teaching at the current center, teacher role (i.e.,

186 head teacher, non-head teacher), education (i.e., less than college graduate, college graduate or

187 more) and nutrition training (i.e., less than 1 time a year, 1 time a year or more). These variables

188 were selected to be examined as covariates because they were found in past literature to be 189 related to mealtime behaviors with children. ${ }^{7,48}$ Teacher age, years as a child care teacher, and

190 years working at the current center were highly correlated and combined into a composite

191 (alpha=0.81). This composite representing experience was used in all subsequent analyses.

\section{Data Analysis}

193 Descriptive measures of central tendency, variability, internal consistency (Cronbach's

194 alpha) and distributions were assessed for all variables. Analyses indicated that all items were

195 normally distributed except for nutrition attitudes. Although both square root and Log 10 were

196 initially conducted, transformations did not make the data more normally distributed. Regression

197 diagnostics were conducted to examine residuals. The P-P plot for the non-transformed attitude

198 variable was observed to follow a pattern of normal distribution. Bivariate analyses were

199 conducted for continuous variables (e.g., experience) and the independent (i.e., nutrition

200 knowledge, attitudes and fruit and vegetable intake) and dependent variables (i.e., observed and

201 self-reported mealtime behaviors) using Pearson correlations. Associations between categorical

202 covariates (education, teacher role and training variables) and the independent and dependent

203 variables were examined using ANOVA. Since the meal environments differed by time, bivariate

204 analyses were conducted between lunchtime and breakfast observations to examine significant

205 differences in observed behavior total scores. A hierarchichal multivariate regression analysis 
206 was conducted on observed teacher mealtime behavior. To control for significant covariates, 207 teacher experience followed by meal type was entered into the model in the first step. In the

208 second step, nutrition knowledge, attitudes and fruit and vegetable intake (independent variables)

209 were consecutively entered into the model (enter). A second hierarchichal multivariate

210 regression analysis was conducted on self-reported teacher mealtime behavior. To control for

211 significant covariates, teacher experience was entered into the model in the first step. In the

212 second step, nutrition knowledge, attitudes and fruit and vegetable intake (independent variables)

213 were consecutively entered into the model (enter). Associations between the observation and

214 mealtime self-report were examined using Pearson correlations. The full reporting of these

215 findings are the focus of a separate study, however, main findings are briefly included in the

216 results. $^{49}$ All analyses were performed using SPSS software (SPSS 21.0).

RESULTS

Teachers were predominantly female (98\%), and non-Hispanic white (84.6\%). Half of

220 teachers $(50.6 \%)$ had a college education or more, while $44.7 \%$ had some college or technical

221 school. Participants were experienced teachers with an average of 14 years of experience and

222 more than 7 years teaching at their current center. The majority (57\%) identified as either head

223 teachers, or $37.6 \%$ as assistant teachers, $2.4 \%$ as special education teachers, and $2.4 \%$ as

224 teacher's aides and most teachers worked full-time (83.5\%). Two-thirds (68\%) of respondents

225 reported receiving nutrition training at least once a year. Mealtimes averaged 23 minutes.

In general, teachers' overall scores for most measures were high. Teachers demonstrated

227 high levels of nutrition knowledge $(\mathrm{M}=9.80, \mathrm{SD}=1.96$, range=3.0-12.0), nutrition attitudes

228 (Median=72.87, interquartile range $(I Q R)=70-75$, range=54-79), self-reported mealtime 
229 behaviors $(\mathrm{M}=121.09, \mathrm{SD}=8.72$, range $=97-141)$ and observed mealtime behaviors $(\mathrm{M}=91.93$, $230 \mathrm{SD}=4.77$, range=82-101). Mean fruit and vegetable intake was found to exceed the minimum 231 recommendation of 3.5 cups per day $(\mathrm{M}=3.88, \mathrm{SD}=1.82$, range $=0.9-10.7)$.

232 There was a positive association between teaching experience and both self-reported $233(\mathrm{r}(83)=.27, \mathrm{p}<.05)$ and observed $(\mathrm{r}(83)=.39, \mathrm{p}<.01)$ mealtime behavior. Mealtime behaviors

234 were not associated with teacher role, nutrition training or level of education (data not reported).

235 Comparisons (t-tests) between breakfast and lunch observations indicate that teachers' overall

236 scores were significantly higher during lunch $(M=92.76, S D=4.69)$ than during breakfast $(M=89$, $237 \mathrm{SD}=3.9), \mathrm{p}<.01$.

238 For self-reported and observed meal time behavior, there were no associations between 239 teacher nutrition knowledge, attitudes, and fruit and vegetable intake with one exception; there 240 was a positive association between self-reported mealtime behavior and attitudes (Table 1). More 241 positive attitudes were associated with higher self-reported mealtime behaviors.

242 Using hierarchical multivariate regression, observed teacher mealtime behavior was 243 regressed on nutrition knowledge, attitudes, and fruit and vegetable intake yielding a significant 244 model (Table 2) with meal type (lunch) and teacher experience associated with higher scores 245 during observations (Model 1). However, after controlling for meal type and teacher experience, 246 none of the independent variables were significantly associated with the overall observed 247 behavior total score (Model 2).

248 In terms of self-reported mealtime behavior (Table 3), teacher experience significantly 249 predicted teacher self-report (Model 1). After controlling for teacher experience, nutrition 250 attitudes were significantly associated with the self-reported behavior total score (Model 2). 
251 Higher scores on the nutrition attitude scale were associated with higher total scores on the 252 teacher mealtime behavior self-report.

253 The analyses of the associations between the observation and mealtime self-report found

254 no overall association between the observation and mealtime self-report. An item analysis

255 yielding a more nuanced set of associations is reported elsewhere. ${ }^{49}$

DISCUSSION

The goal of this study was to examine the association between nutrition knowledge, 259 attitudes and fruit and vegetable intake among Head Start teachers and their classroom mealtime

260 behaviors with children. The study found that teacher nutrition knowledge, attitudes and fruit and 261 vegetable intake were not related to observed behavior during mealtimes in the classroom.

262 Nutrition attitudes were positively associated with teacher self-reported classroom mealtime

263 behavior, however, only accounted for a small percentage of the variance in the model. Overall 264 study findings showed that teacher mealtime behavior was significantly associated with teacher 265 experience.

266 Direct observation has been considered the gold standard when attempting to measure

267 behavior. ${ }^{50}$ It is somewhat surprising, therefore, that the independent variables (i.e., nutrition

268 knowledge, attitudes and fruit and vegetable intake) were not associated with observed

269 interactions within the classroom. Even more intriguing was how teachers were often engaging

270 in behaviors considered to be 'best practices' such as frequently engaging in talk with the

271 children about the foods they were eating and eating fruits and vegetables during mealtimes with 272 children. 
Teachers demonstrated high levels of nutrition knowledge, positive nutrition attitudes,

274 and reported better than average fruit and vegetable intake. Based on the Health Belief Model, ${ }^{33}$

275 we expected these factors to be associated with more optimal classroom behaviors (e.g., talking

276 with the children about the foods they were eating, enthusiastically role modeling healthy eating)

277 and were surprised that they were not. One possible explanation for this lack of association may

278 be related to how the behaviors with the observational tool are coded. For example, the coding

279 choices for most behaviors were 'none', '1-2 times' or ' 3 or more times'. If a teacher praised a

280 behavior 3 times, they were in the same category as a teacher who praised a behavior 10 times.

281 Given that the teachers' overall results on the observations were high, it is possible that coding

282 limitations may not have captured the degree of variability that actually exists. Also, teachers

283 under observation may in fact respond with more optimal behaviors. ${ }^{51}$

284 Head Start is known for its strong nutrition guidelines and teacher training. ${ }^{36,52}$ Working

285 in Head Start programs has been associated with practicing healthier feeding practices such as

286 modeling healthy eating and teaching children about nutrition compared to other child care

287 contexts. ${ }^{47}$ Head Start providers are also more likely to use family style feeding, another

288 recommended healthy feeding practice, at higher rates than CACFP and non-CACFP providers. ${ }^{47}$

289 All Head Start programs are required by Federal Program Performance Standards to provide

290 nutrition training for their staff ${ }^{36}$ and research has shown that Head Start teaching training

291 influences the quality of nutrition-focused instruction. ${ }^{53}$ For this study, Head Start classrooms

292 were originally selected to limit variability that might occur across centers in order to be able to

293 capture individual teacher variability. Findings suggest that practices may be so uniformly

294 accepted that despite individual teacher differences, teachers behave with great consistency.

295 Head Start trainings seem to be working well and contributing to optimal mealtime behaviors. 
Nutrition knowledge in this study refers to knowledge of basic healthy eating (e.g., How

297 many cups of vegetables should a moderately active adult eat per day? What message supports a

298 healthy diet?). Others have found that the experience, education, and positive nutrition attitudes

299 of caregivers are associated with feeding behavior ${ }^{7}$ and therefore it was expected that individual

300 teacher nutrition knowledge would be associated with teacher classroom behavior. The lack of

301 support for this finding suggests that although the Head Start teachers have basic healthy eating

302 knowledge, their overall experience appears to be key to engaging in optimal mealtime

303 behaviors.

304 It was hypothesized that higher fruit and vegetable intake among teachers would be

305 associated with more optimal mealtime behaviors with children, possibly through modeling of

306 healthy behaviors. ${ }^{32}$ The lack of association between their own health behavior (fruit and

307 vegetable intake) and mealtime behavior with children suggests that teacher fruit and vegetable

308 intake may be independent from how teachers behave during meals once they are in the

309 classroom. There may be several reasons for this. One explanation may be that meals are

310 generally proscribed and teachers have little input into what foods are offered. Additionally,

311 teacher's reporting of fruit and vegetable consumption was also higher than might have been

312 expected. Others have reported poorer diets among Head Start teachers, ${ }^{9}$ potentially suggesting a

313 response bias, with teachers wanting to report healthier habits. For example, the measure for

314 body weight (data not reported), a validated body size assessment scale, indicates that more than

315 half of participants were overweight or obese, further raising the question as to whether fruit and

316 vegetable intake was accurately reported. Some research has shown that those who are

317 overweight/obese are more likely to report that their diets are healthier than they actually are. ${ }^{54}$ 
Teacher experience was found to be associated with both observed and self-reported

319 mealtime behavior. Previous research has also found an association between experience and

320 optimal mealtime behaviors. ${ }^{7}$ It is likely that older, more experienced teachers have had more

321 exposure to curriculum involving nutrition, contributing to more expertise and confidence in

322 working with children. Head Start teachers in this study, on average, had worked in Head Start

323 centers for more than a decade demonstrating low turnover, also potentially benefitting the

324 children in their care.

An important strength of this study is the utilization of a direct observation to gather

326 mealtime behavior data. In addition, the study enrolled approximately $1 / 3$ of Head Start teachers

327 in the state. The study is not without limitations, however. For one, many of the constructs of

328 interest did not have well-developed measures. For example, the authors were unable to identify

329 a nutrition knowledge measure that captured basic principles of healthy eating. Some measures

330 required highly specific knowledge (e.g., role of particular nutrients), ${ }^{7}$ while others required

331 ratings of 'healthy' with little consensus around the correct answers. ${ }^{47}$ Still others were

332 developed outside of the United States and deemed culturally unsuitable for U.S. populations. ${ }^{55}$

333 As a result, the authors adapted existing measures or developed their own. This creates

334 limitations (i.e., measures not validated elsewhere), however, given the dearth of existing

335 measures, moves the study of these constructs forward, despite the limitations. In addition,

336 internal consistency scores for measures were also somewhat low. Furthermore, a fruit and

337 vegetable screener was used to represent dietary intake. Other dietary measures were considered

338 (e.g., Healthy Eating Index, Food Frequency Questionnaire) but excluded due to participant

339 burden. While others have used the FVS in the past and there is high convergent validity

340 between the FVS and dietary recall, the measure does not capture the full range of dietary intake. 
In terms of mealtime behaviors, there were also limited tools available for observing

342 preschool classrooms. For the purposes of this study, the authors adapted an existing observation

343 measure. The original instrument included 9 items to assess staff feeding behaviors; the final

344 version included 47 items capturing a much wider range of behaviors (e.g., reasoning,

345 negotiation, support of self-regulation). The coding structure of the original measure (which was

346 adapted in this study), however, had a limited range for coding frequency of behaviors which

347 may have contributed to weaker than expected associations. Also, in general, observations

348 conducted only at one point in time may not have captured overall behavior.

IMPLICATIONS FOR RESEARCH AND PRACTICE

The results of this study have important implications for child care contexts. As has been

352 established in the literature, optimal mealtime behavior among teachers is significantly

353 associated with more teacher experience. ${ }^{7}$ While retaining preschool teachers is a challenge that

354 extends well beyond the focus of this study (e.g., pay, benefits), consideration of the associations

355 between teacher mealtime behavior and their experience may provide an avenue for enhancing

356 teacher retention. Additionally, the focus on Head Start specifically was intended to reduce

357 variability across types of centers to be able to focus more closely on individual level variables

358 of teachers. Given the fairly high degree of consistency and behaviors across teachers, one

359 question that emerges is whether this is unique to Head Start programs. One possibility, not

360 examined here, is that Head Start mealtime guidelines may be enforced to such a degree that

361 individual variability in teacher behavior is reduced. The existence of nutrition policies within a

362 child care context has been found to be associated with promoting healthy mealtime behaviors, 
363 as compared to programs that did not have any mealtime policies. ${ }^{8}$ Future research would benefit 364 from a more systematic examination of this hypothesis.

365 Based on study findings and limitations, recommendations for future studies include

366 measuring the knowledge of procedural practices/adherence to specific Head Start mealtime

367 guidelines in association with mealtime behaviors; replicating this study in child care teacher

368 populations that operate under different conditions (e.g., food availability); developing more

369 suitable measures for the field (e.g., nutrition knowledge, mealtime behavior); collecting data on

370 all aspects of diet, not just fruit and vegetable consumption; observing breakfast only or lunch

371 only or including designs with samples large enough to control for different mealtime settings;

372 examining whether childcare provider variables (e.g., knowledge, attitudes) relate to child

373 outcomes (e.g., child fruit and vegetable intake); and conducting several consecutive

374 observations on the same teacher as multiple observations over several days would likely yield

375 more reliable data. ${ }^{56}$

\section{REFERENCES}

1. Centers for Disease Control and Prevention. Vital Signs: Progress on Childhood Obesity. 2013. Available at www.cdc.gov/vitalsigns/ChildhoodObesity/index.html Last accessed December 30, 2013.

2. Forum on Child and Family Statistics. Percentage of Children ages 3-6 in Center-Based Care. 2016. Available at www.childstats.gov/americaschildren/tables/fam3b.asp Last accessed April 1, 2016.

3. Larson N, Ward D, Neelon S, et al. What role can child-care settings play in obesity prevention? A review of the evidence and call for research efforts. J Am Diet Assoc 2011;111:1343-62.

4. Hendy HM, Raudenbush B. Effectiveness of teacher modeling to encourage food acceptance in preschool children. Appetite 2000; 34: 61-76.

5. Birch L, Zimmerman S, Hind H. The influence of social-affective context on the formation of children's food preferences. Child Dev 1980; 51: 856-861.

6. Byrd-Bredbenner C, Marecic M, Bernstein, J. Development of a nutrition education curriculum for head start children. Soc Nutr Educ 1993; 25:134-139. 
7. Nahikian-Nelms M. Influential factors of caregiver behavior at mealtime: a study of 24 child-care programs. J Am Diet Assoc 1997; 97: 505-509.

8. Erinosho TO, Hales DP, McWilliams CP, et al. Nutrition policies at child-care centers and impact on role modeling of healthy eating behaviors of caregivers. J Acad Nutr Diet 2012; 112: 119-124.

9. Sharma S, Dortch KS, Byrd-Williams C, et al. Nutrition-related knowledge, attitudes, and dietary behaviors among head start teachers in Texas: A cross-sectional study. J Acad Nutr Diet 2013;113: 558-562.

10. Dev D, Spiers K, McBride B, et al. Head start and child care providers' motivators, barriers and facilitators to practicing family style meal service. Early Child Res $Q 2014$; 29: 649-659.

11. Vaughn AE, Ward DS, Fisher JO, et al. Fundamental constructs in food parenting practices: a content map to guide future research. Nutr Rev 2016; 74:98-117.

12. Johnson SL. Developmental and environmental influences on young children's vegetable preferences and consumption. Adv Nutr 2016; 7: 220S-231S.

13. Rollins BY, Savage JS, Fisher JO, et al. Alternatives to restrictive feeding practices to promote self-regulation in childhood: a developmental perspective. Pediatr Obes 2016. doi 10.1111/ijpo.12071.

14. Shloim N, Edelson LR, Martin N, et al. Parenting styles, feeding styles, feeding practices, and weight status in 4-12 year-old children: a systematic review of the literature. Front Psychol 2015; 6: 1849.

15. Gable S, Lutz S. Nutrition socialization experiences of children in the head start program. J Am Diet Assoc 2001; 101: 572-577.

16. Ventura A, Birch L. Does parenting affect children's eating and weight status? Int J Behav Nutr Phys Act 2008; 5:15.

17. Birch L, Marlin D, Rotter J. Eating as the "means" activity in a contingency: effects on young children's food preferences. Child Dev 1984; 55: 432-439.

18. Newman J, Taylor A. Effect of a means: end contingency on young children's food preferences. J Exp Child Psychol 1992; 64: 200-216.

19. Hertzler A. Children's food patterns - A review. J Am Diet Assoc. 1983; 83, 555-560.

20. Fisher J, Birch L. Maternal restriction of young girls' food access is related to intake of those foods in an unrestricted setting. FASEB J 1996;10: A225.

21. Hennessy E, Hughes SO, Goldberg JP, et al. Permissive parental feeding behavior is associated with an increase in intake of low-nutrient-dense foods among American children living in rural communities. J Acad Nutr Diet 2012;112: 142-148.

22. Birch L, Birch D, Marlin D, et al. Effects of instrumental eating on children's food preferences. Appetite 1982; 3:125-134.

23. Black M, Aboud F. Responsive feeding is embedded in a theoretical framework of responsive parenting. J Nutr 2011; 141: 490-494.

24. Johnson S. Improving preschooler's self-regulation of energy intake. Pediatrics 2000; 106:1429-35.

25. Tovar A, Vaughn A, Fallon M, et al. Provider's response to child eating behaviors: a direct observation study. Appetite 2016; 105: 534-541.

26. Golan M, Crow S. Parents are key players in the prevention and treatment of weightrelated problems. Nutr Rev 2004; 62: 39-50. 
27. Crockett S, Sims L. Environmental influences on children's eating. JNEB 1995; 27: 235249.

28. Freedman MR, Alvarez KP. Early childhood feeding: assessing knowledge, attitude, and practices of multi-ethnic child-care providers. J Am Diet Assoc 2010;110: 447-451.

29. Lumeng J, Kaplan-Sanoff M, Shuman S, et al. Head start teachers' perceptions of children's eating behavior and weight status in the context of food scarcity. JNEB 2008; 40: 237-243.

30. Hughes C, Gooze R, Finkelstein D, et al. Barriers to obesity prevention in head start. Health Aff 2010; 29: 454-62.

31. Bronfenbrenner, U. The Ecology of Human Development: Experiments in Nature and Design. Harvard University Press: Cambridge, MA, 1979.

32. Bandura, A. Self-efficacy: The Exercise of Control. MacMillan: New York, NY, 1997.

33. Rosenstock I, Strecher V, Becker M, et al. Social learning theory and the health belief model. Health Educ Q 1988; 15:175-183.

34. Bleich S, Bennett W, Gudzune K, et al. Impact of physician BMI on obesity care and beliefs. Obesity 2012; 20: 999-1005.

35. Crawford P, Gosliner W, Strode P, et al. Walking the talk: fit WIC wellness programs improve self-efficacy in pediatric obesity prevention counseling. Am J Public Health 2004; 94: 1480-1485.

36. Administration for the Office of Children and Families. Office of Head Start. 2013. Available at https://www.acf.hhs.gov/ohs Last Accessed April 14, 2014.

37. Gooze R, Hughes C, Finkelstein D, et al. Reaching staff, parents, and community partners to prevent childhood obesity in head start. Prev Chronic Dis 2010; 7: A54

38. Whitaker R, Becker B, Herman A, et al. The physical and mental health of head start staff: the Pennsylvania head start staff wellness survey, 2012. Prev Chronic Dis 2013. doi http://dx.doi.org/10.5888/pcd10.130171.

39. Whitaker R, Orzol M. Obesity among US urban preschool children: relationships to race, ethnicity, and socioeconomic status. Arch Pediatr Adolesc Med 2006; 160: 578-584.

40. Rhode Island Department of Education. Rhode Island Department of Education Child and Adult Care Food Program. Available at http://www.ride.ri.gov/Portals/2/Uploads/Documents/CACFP\%20Resources/CACFP\%20 New\%20Meal\%20Pattern/CACFP_childmealpattern.pdf Last Accessed March 31, 2014.

41. United States Department of Agriculture. Choose My Plate. 2014. Available at http://www.choosemyplate.gov/ Last Accessed August 2, 2014.

42. National Cancer Institute. Fruit and Vegetable Screeners in the Eating at America's Table Study. 2013. Available at http://appliedresearch.cancer.gov/diet/screeners/fruitveg/validity.html Last Accessed March 31, 2014.

43. Thompson F, Subar A, Smith A, et al. Fruit and vegetable assessment: performance of 2 new short instruments and a food frequency questionnaire. J Am Diet Assoc 2002; 102:1764-72.

44. Ward D, Hales D, Haverly K, et al. An instrument to assess the obesogenic environment of child care centers. Am J Health Behav 2008; 32: 380-386.

45. Landis R, Koch G. The measurement of observer agreement for categorical data. Biometrics 1977; 33: 159-174. 
46. Ward D, Mazzucca S, McWilliams C, et al. Use of the environment and policy evaluation and observation as a self-report instrument to measure nutrition and physical activity environments in child care settings: validity and reliability evidence. Int J Behav Nutr Phys Act 2015; 12:124.

47. Dev D, McBride B, Speirs K, et al. Predictors of head start and child care providers' healthful and controlling feeding practices with children aged 2 to 5 years. J Acad Nutr Diet 2014; 114: 1396-1403.

48. Hughes SO, Patrick H, Power T, et al. The impact of child care providers' feeding on children's food consumption. J Dev Beh Pediatr 2007; 28: 100-107.

49. Fallon M, Halloran K, Gorman K, et al. Self-reported and observed feeding practices of Rhode Island head start teachers: knowing what not to do. Appetite. Manuscript submitted for publication.

50. Briesch A, Chafouleas S, Riley-Tilman TC. Direct Behavior Rating. Guilford Publications: New York, NY, 2016

51. Wickstrom G, Bendix T. The "Hawthorne" Effect: What did the original Hawthorne studies actually show? Scand J Work Enviror Health 2000; 26: 363-367. Dev D, McBride B. Academy of Nutrition and Dietetics benchmarks for nutrition in child care 2011: are child care providers across contexts meeting recommendations? J Acad Nutr Diet 2013; 113: 1346-1353.

52. Dev D, McBride B. Academy of Nutrition and Dietetics benchmarks for nutrition in child care 2011: Are child care providers across contexts meeting recommendations? J Acad Nutr Diet 2013; 113: 1346-1353.

53. Carraway-Stage V, Hensen S, Dipper A, et al. Understanding the state of nutrition education in the head start classroom: A qualitative approach. J Health Educ 2013; 45: 52-62.

54. Archer E, Hand GA, Blair SN. Validity of U.S. nutritional surveillance: national health and nutrition examination survey caloric energy intake data, 1971-2010. PLoS ONE 2013. doi 10.1371/journal.pone.0076632

55. Parmenter K, Ward J. Development of a general nutrition knowledge questionnaire for adults. Eur J Clin Nutr 1999; 53: 298-308.

56. Menard S. Handbook of Longitudinal Research: Design, Measurement and Analysis. Elsevier: Boston, MA, 2007. 